\title{
REVIEWS.
}

\section{RECENT ADVANCES IN LARYNGOLOGY AND OTOLOGY.}

By R. Scott Stevenson, M.D., F.R.C.S., (Edin.) J. \& A. Churchill, Ltd. 1935. Price 15/-.

In this compact, clearly printed and lavishly illustrated book of 22 chapters, the author has presented an excellent resumé of current knowledge concerning an equal number of subjects bearing on diseases of the throat, nose and ear. We would suggest, however, that the title of a second edition might include "Rhinology" in order to retain the long recognized and inseparable triology of this speciality, and to avoid any fear or presumption on the part of the uninitiated that diseases of the nose and the accessory sinuses are not to be found within the compass of the author's review. Nevertheless it may safely be predicted that the five years spent in the preparation of this volume will find their due reward if only because of the stress laid on diagnosis and treatment in which those useful handmaids, skiagraphy and radio-therapy, play an increasing part.

So clearly, are the chosen subjects presented that the volume will make a special appeal to " medical practitioners, house surgeons, clinical assistants and junior oto-laryngologists ", and " post-graduates working for higher qualifications such as D.L.O. and F.R.C.S. examinations," while "established oto-laryngologists will find it a convenient compendium of modern work." Readers who want further information on any topic selected by the author, will find a list of biographical references at the end of each chapter.

It is impossible to select for special mention any particular field surveyed because the whole is so good. But we would state that the reviews of "Tuberculosis of the Larynx," " Radiological Examination of the Nasal Accessory Sinuses," "Hearing Tests," "Bronchoscopy and Oesophagoscopy," "The Conservative Treatment of Chronic Middle Ear Suppuration" and of that evergreen subject "The Tonsil Problem " are specially valuable. Interesting and important discussions on "Agrunulocytoses," "The Surgical Treatment of Facial Paralysis," and the cerebral complications of disease of the nose, ear and throat, viz., " Meningitis " and " Cerebral Abscess" are also included.

A general and comprehensive "General Index" concludes what will surely prove to be a very useful addition to the bookshelves of all students of medicine.

\section{BIRTH CONTROL AND ITS OPPONENTS.}

By Frank W. White, L.R.C.P. \& S.E. [With Foreword by Lord Horder, K.C.V.O., M.D.]

John Bale, Sons and Danielsson, Ltd. 1935. Price $3 / 6$ net.

At the present time one set of writers are deploring the falling birth rate, whereas another group are decrying an even more rapidly increasing population and see therein the cause of all the ills of which society is a victim. The late wart and the present unemployment, for example, are directly due to this cause and the author of the present volume is a supporter of this theory. Naturally, the removal of the cause will cure the disease and for this purpose the author recommends birth control, the arguments for and against which the reader will find fully discussed in a most interesting and exhaustive manner.

\section{THE ANEMIAS.}

2nd Edition.

By Janet M. Vaughan, D.M., M.R.C.P. Oxford University Press. 1936. Price $12 / 6$.

The call for a second edition of this book within less than two years reveals the important place which it has come to occupy and the increase in its size indicates the rapidity with which additions are being made to our knowledge of hæmatology. We know of no more comprehensive treatise on hæmatology in the English language. 
The general plan of the volume is unaltered, but opportunity has been taken to incorporate all the important recent work and to add new charts and several rather fine coloured plates. The book is certainly one which must be in the hands not only of every clinician but also of the research worker as its pages simply teem with problems waiting to be solved. Indeed, if we would criticize, it would be that this aspect of the subject is unduly prominent, the disconcerting views regarding so many points on which the author does not seem to be in a position to make a decision. However, as already remarked, it is a stimulus to further work that the book will be specially valuable, a feature of medical literature which is unfortunately somewhat rare.

\section{PARENTERAL THERAPY.}

By W. F. Dutton, M.D., and G. B.

LAKE, M.D. pp. 386 with 90 illustrations. Bailliére, Tindall \& Cox. 1936.

$$
\text { Price 34/-. }
$$

This is a volume which will be welcomed by most physicians and surgeons and which should be on the shelves of every library attached to a ward unit.

It consists of three parts. The first is devoted to a detailed description, illustrated when necessary, of all the common diagnostic and therapeutic operations carried out in the modern practice of medicine and surgery, e.g., venepuncture, saline transfusion, blood transfusion; exploration of pleura, pericardium and peritoneum; the induction of artificial pneumothorax; lumbar puncture, ventricular puncture and ventriculography; the exploration of joints ; the induction of local and spinal anæsthesia, and the injection treatments of varioose veins and hæmorrhoids.

The second and third sections of the book are to our mind the least instructive but they may be of help in some circumstances. The former is an alphabetical list of diseases with the various drugs which are administered for their relief by other routes than per os. but, however, without any indication of their relative value. The latter is a list, also alphabetically arranged, of all drugs, vaccines and hormones which are administered intramuscularly and subcutaneously.

\section{HINTS TO}

\section{PROBATIONER NURSES IN MENTAL HOSPITALS.}

\author{
(Third Edition)
}

By Richard Eager, O.B.E., M.D., Messrs. H. K. Lewis \& Co., Ltd. 1936. Price 8/6.

This is a book which can be warmly recommended to all nurses having the care of mental patients but it will also be read with advantage by general nurses as well, and even medical men.

The book is divided into 2 Parts. Part 1 deals with general principles, e.g., " Ward Duties," "Psychology" and "Dreams." In Part 2 are discussed the main types of mental disorder, special emphasis being laid on the clinical pictures, which the nurse can observe for herself and the information for which the physician relies upon her. The various descriptions are excellent and in many instances are distinctly enhanced by characteristic photographs of patients.

\section{BRITISH MASTERS OF MEDICINE.}

Edited by Sir D'Arcy Power. Messrs.

Baillière, Tindall \& Cox. pp. 242. 32

Plates. 1936. Price $7 / 6$.

This volume consists of a series of biographical sketches which have appeared during the recent months in the pages of the Medical Press \& Circular. Than the lives of our medical heroes there is no subject of more perennial interest and thus we have no doubt that these sketches will be welcomed in their more permanent form by many medical men.

In all there are 24 biographies extending from Harvey of the sixteenth century to James Mackenzie, Patrick Manson and Robert Jones all of the latter many of us must have known in the flesh. Consequently they are of unequal length and detail and not always commensurate with the mark made by these heroes on our 